\title{
A Carbonate Controlled-Addition Method for Amorphous Calcium Carbonate Spheres Stabilized by Poly(acrylic acid)s
}

\author{
Shu-Chen Huang, Kensuke NAKA* and Yoshiki CHUJO*
}

\section{Table of Contents}

Figure s1. SEM images of the $\mathrm{CaCO}_{3}$ products incubated in the mother solution for a long time, (a) sample 18, (b) sample 19, (c) sample 20, and (d) sample 21 in Table 4.

Figure s2. SEM images of the ACC samples after thermal treatment at $400{ }^{\circ} \mathrm{C}$ for (a) $1 \mathrm{~h}$, sample 22 , (b) $3 \mathrm{~h}$, sample 23, and (c) $5 \mathrm{~h}$, sample 24 in Table 5.

Figure s3. SEM images of the $\mathrm{CaCO}_{3}$ products with increasing of concentrations of calcium reagents and repeating uniting of PAA, (a) sample 25, and (b) sample 26 in Table s1.

Figure s4. Photos of the PAA- $\mathrm{CaCl}_{2}$ complexation aqueous solution: right side of the sample: the complexation time $=3 \mathrm{~min}$, left side of the sample: the complexation time $=24 \mathrm{~h}$.

Table s1. Effect of the Concentrations of the Calcium Reagents and the Repeating Unit of PAA on the Precipitation of $\mathrm{CaCO}_{3}$.

Table s2. Effect of the Complexation Time in the Higher Molar Mass of PAA $(\mathrm{Mw}=25000)$ on Mineralization of $\mathrm{CaCO}_{3}$. 


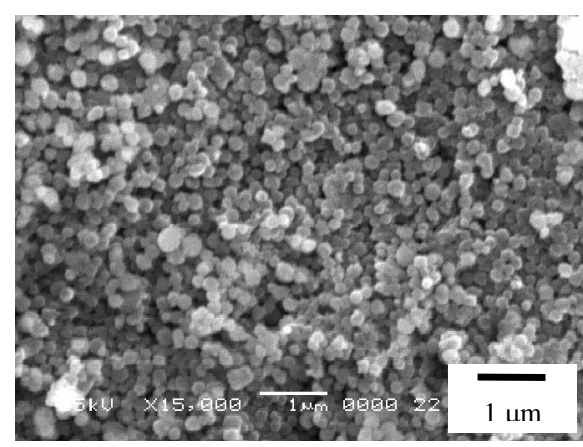

(a)

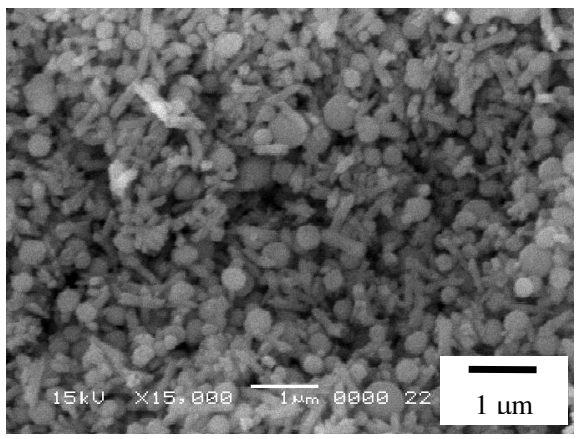

(c)

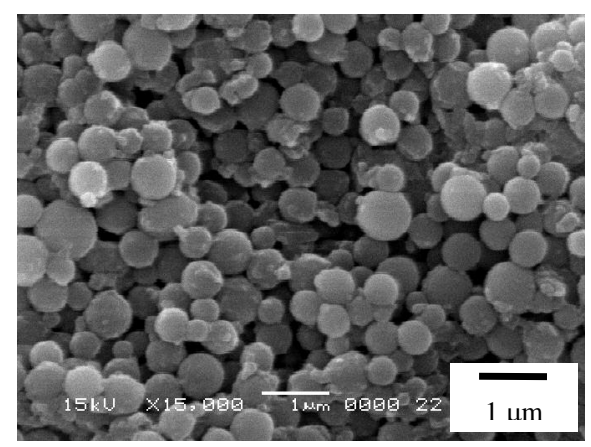

(b)

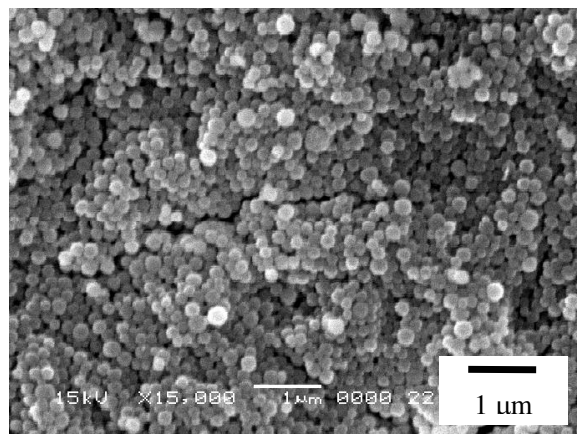

(d)

Figure s1. SEM images of the $\mathrm{CaCO}_{3}$ products incubated in the mother solution for (a) 10 days, stirring time $=3$ min, (b) 3 days, stirring time $=24$ h, (c) 5 days, stirring time $=24 \mathrm{~h}$, and (d) 90 days, stirring time $=3 \mathrm{~min}$, corresponding to sample 18, 19, 20, and 21 in Table 4, respectively.

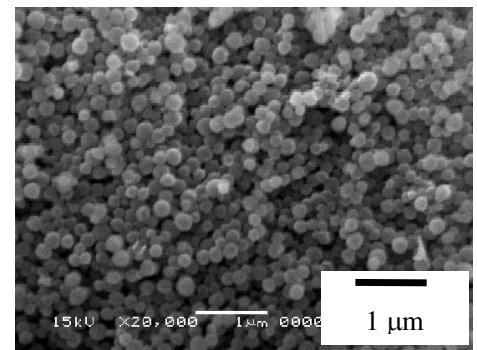

(a)

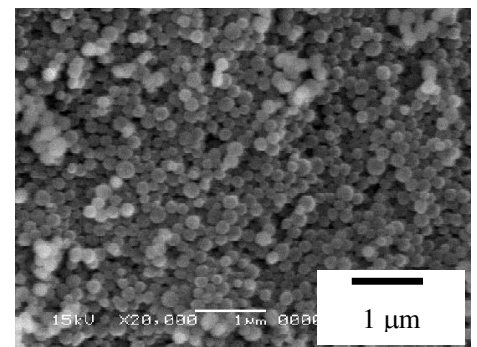

(b)

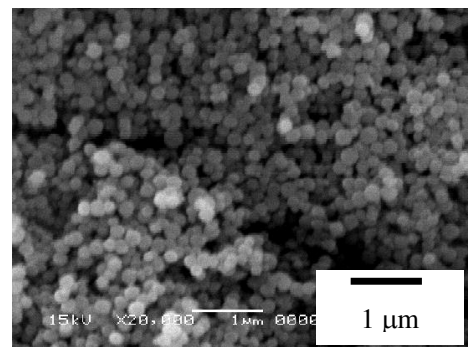

(c)

Figure s2. SEM images of the ACC samples after thermal treatment at $400{ }^{\circ} \mathrm{C}$ for (a) $1 \mathrm{~h}$, (b) $3 \mathrm{~h}$, and (c) $5 \mathrm{~h}$, corresponding to sample 22,23 , and 24 in Table 5, respectively. 
Table s1. Effect of the Concentrations of the Calcium Reagents and the Repeating Unit of PAA on the Precipitation of $\mathrm{CaCO}_{3}{ }^{\mathrm{a}}$.

\begin{tabular}{cccccc}
\hline $\begin{array}{c}\text { sample } \\
\text { no }\end{array}$ & $\begin{array}{c}{\left[\mathrm{Ca}^{2+}\right],} \\
\mathrm{mM}\end{array}$ & $\begin{array}{c}{\left[-\mathrm{COO}^{\ddagger}\right],} \\
\mathrm{mM}\end{array}$ & stirring time & polymorphism ${ }^{\mathrm{b}}$ & $\begin{array}{c}\text { particle size } \\
{\text { of } \mathrm{CaCO}_{3}{ }^{\mathrm{c}}}^{\mu \mathrm{m}}\end{array}$ \\
\hline 25 & 10 & 4 & $3 \mathrm{~min}$ & calcite & - \\
26 & 6 & 2 & $3 \mathrm{~min}$ & amorphous & $0.15-0.5$ \\
27 & 5 & 1.5 & $3 \mathrm{~min}$ & amorphous & $0.15-0.5$ \\
28 & 5 & 1.5 & $18 \mathrm{~h}$ & calcite & $0.3-0.8$
\end{tabular}

${ }^{a}$ Experimental condition: PAA Mw $=5000$, the $\mathrm{pH}$ value of the PAA aqueous solution was adjusted to 9 with $\mathrm{NaOH}_{(\mathrm{aq})}$. ${ }^{\mathrm{b}}$ Polymorphism was characterized by XRD and FTIR. ${ }^{\mathrm{c}}$ The size of $\mathrm{CaCO}_{3}$ particles was measured by SEM.

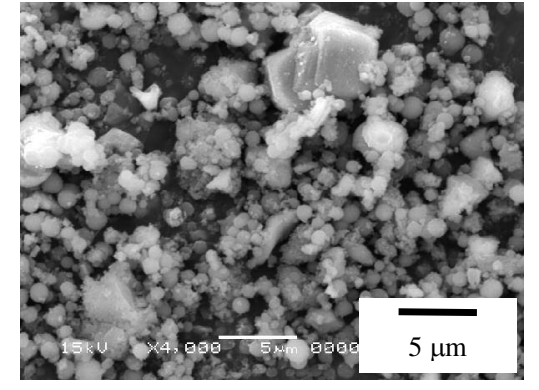

(a)

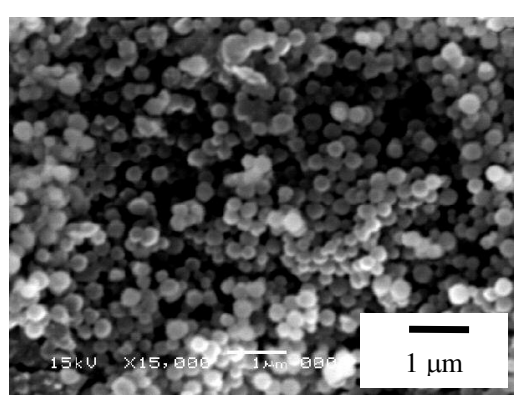

(b)

Figure s3. SEM images of the $\mathrm{CaCO}_{3}$ products with increasing of concentrations of calcium reagents and repeating uniting of PAA, (a) sample 25, and (b) sample 26 in Table s1.

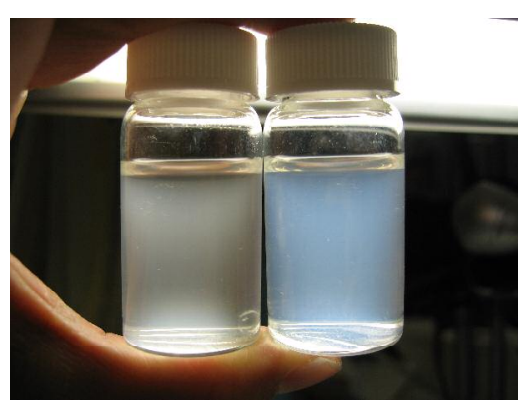

Figure s4. Photos of the $\mathrm{PAA}-\mathrm{CaCl}_{2}$ complexation aqueous solution: right side of the sample: the complexation time $=3 \mathrm{~min}$, left side of the sample: the complexation time $=24 \mathrm{~h}$. 
Table s2. Effect of the Complexation Time in the Higher Molar Mass of PAA $(\mathrm{Mw}=25000)$ on Mineralization of $\mathrm{CaCO}_{3}{ }^{\mathrm{a}}$.

\begin{tabular}{|c|c|c|c|c|}
\hline $\begin{array}{l}\text { sample } \\
\text { no }\end{array}$ & $\begin{array}{l}\text { stirring } \\
\text { time }\end{array}$ & polymorphism $^{\mathrm{b}}$ & $\begin{array}{l}\text { particle size of } \\
\mathrm{CaCO}_{3},{ }^{\mathrm{c}} \mu \mathrm{m}\end{array}$ & yield, ${ }^{\mathrm{d}} \%$ \\
\hline 29 & $3 \mathrm{~min}$ & amorphous & $0.15-0.5$ & 54 \\
\hline 30 & $1 \mathrm{hr}$ & amorphous & $0.2-0.8$ & 43 \\
\hline 31 & $3 \mathrm{hrs}$ & amorphous + vaterite + calcite & $0.2-1.2$ & 64 \\
\hline 15 & $18 \mathrm{hrs}$ & amorphous + vaterite + calcite & $0.3-1.3$ & 45 \\
\hline
\end{tabular}

${ }^{\mathrm{a}}$ Experimental condition: $\left[\mathrm{Ca}^{2+}\right]=\left[\mathrm{CO}_{3}{ }^{2-}\right]=5 \mathrm{mM}$, [repeating unit of PAA $]=2 \mathrm{mM}, \mathrm{PAA} \mathrm{Mw}=$ 25000, the $\mathrm{pH}$ value of the PAA aqueous solution was adjusted to 9 with $\mathrm{NaOH}_{(\mathrm{aq})}$. ${ }^{\mathrm{b}}$ Polymorphism was characterized by XRD and FTIR. ${ }^{\mathrm{c}}$ The size of $\mathrm{CaCO}_{3}$ particles was measured by SEM. ${ }^{\mathrm{d}}$ The yield was calculated by the weight of final product compared with the theoretical weight of $\mathrm{CaCO}_{3}$ from added calcium reagents. 